\title{
STUDY OF DEVELOPMENT OF BONY LABYRINTH IN DRY FETAL
} TEM PORAL BONES

\section{Anjali Gosavi ${ }^{* 1}$, Rekha Hiremath ${ }^{2}$.}

*1 Professor \& HOD, Dept. of Anatomy, Ashwini Rural Medical College, Solapur, Maharsahtra, India.

${ }^{2}$ Assistant Professor, Dept. of Anatomy, S.Nijalingappa M edical College, Bagalkot, Karnataka, India.

\section{ABSTRACT}

Introduction: Development of the human inner ear primordium is a sophisticated process that proceeds rapidly in a short period of time. After numerous processes and developmental stages, the mature organs of hearing and balance are perfected before delivery.

Aim: To trace the development of the normal fetal bony labyrinth at different age of the developing fetus.

Materials and Methods: 30 petrous temporal bones of human fetuses were studied, gestational age ranging from 4 to 7 lunar months. Various parameters of the bony labyrinth in dry fetal temporal bones were recorded.

Conclusion: A new regression equation has been derived to predict CR length from length of cochlea and height of lateral semicircular canal. As fetal cochlear development correlates with the surrounding petrosal morphology, studies concerning the relationship between the petrous bone measurement and genetic predisposition to congenital deafness can be useful in diagnosis of causes of congenital deafness.

KEY WORDS: Bony Labyrinth, Dry Fetal Temporal Bones, Fetal Cochlea, Lateral Semicircular Canal.

Address for Correspondence: Prof. Dr. Anjali Gosavi, Professor \& HOD, Dept. of Anatomy, Ashwini Rural Medical College, Solapur, Maharsahtra, India. E-Mail: dr.anjaligosavi@gmail.com

\section{Access this Article online}

\section{Quick Response code}

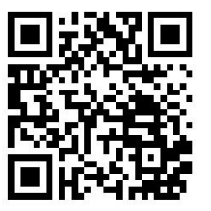

DOI: $10.16965 /$ ijar.2017.210

Web site: International Journal of Anatomy and Research

ISSN 2321-4287

www.jjmhr.org/ijar.htm

Received: 31 Mar 2017

Peer Review: 01 Apr 2017

Revised: 03 Apr 2017
Accepted: 08 M ay 2017

Published (0): 30 Jun 2017

Published (P): 30 Jun 2017

\section{INTRODUCTION}

Inner ear or internal ear is called as labyrinth because of its intricate and irregular shape. It is a complex of membranous sacs and ducts. It is made up of osseous and membranous labyrinth; postnatally it is enclosed in the osseous otic capsule. The membranous labyrinth is contained within the bony labyrinth, sandwiched between these two is the perilymph and within the membranous labyrinth is present the endolymph. The osseous labyrinth is surrounded by thin fibrous membrane and is closely attached to petrous segment of temporal bone. The membranous labyrinth is characterized by three parts: the vestibule, the semicircular canals and the cochlea. The cochlea is situated in the anterior part of the labyrinth, and is responsible for hearing sense, while the vestibule and semicircular canals are the organs responsible for the function of balance [1,2].

Development of the human inner ear primordium is a sophisticated process that proceeds rapidly in a short period of time. The otic placode begins to form a thickening of the ectoderm bilaterally at the head and sinks into the head mesenchyme. Next stages include the otic 
vesicle formation which further will differentiate into semi-circular canals and coils of cochlea. The superior canal is completed first in $6^{\text {th }}$ week. The posterior canal develops next and the lateral canal is the last to develop. After numerous processes and developmental stages, the mature organs of hearing and balance are perfected before delivery [3].

The development of inner ear proceeds in a complicated manner, therefore the analysis of its morphogenesis is of utmost importance in developmental sciences, as well as to otolaryn gologists in defining syndromes affecting cochlea, vestibular and semicircular canal morphology.

To the best of our knowledge, there is no adequate literature that provides measurements of bony labyrinth in fetal dry temporal bones. So our study provides detailed data regarding measurements of bony labyrinth in fetal dry temporal bones, the knowledge of which can be helpful for otolaryngologists, radiologists and anatomists too.

\section{MATERIALS AND METHODS}

In this study 30 petrous temporal bones of human fetuses were included. The fetuses were supplied by the department of Obstetrics and Gynaecology, Chatrapati Shivaji Sarvopachar Rugnalaya, Solapur. M alformed fetuses were not included in our study. The study was preapproved by ethical committee of Dr.V.M. M edical College Solapur. Gestational age ranged from 4 to 7 lunar months, according to protocol and CR length measured before maceration. After measuring $C R$ length, fetuses were kept in running tap water for maceration. It took 4 to 8 months to remove soft tissue attached to the bones. Periosteum was also removed for visualization of anatomical landmarks.

M easurements taken were as follows:

1) Cochlear length 2) Cochlear height 3) Cochlear breadth 4) Length of petrous bone 5) Anterior semicircular canal length and height 6) Posterior semicircular canal length and height 7) Lateral semicircular canal length and height. The collected data was tabulated and analyzed by SPSS software V16.0. Regression equation was also obtained. Comparison between age groups was done by ANOVA Test. Comparison between right and left side of each parameter was done by unpaired t test.

\section{RESULTS}

Table 1: Parameters of bony labyrinth in different age groups (age in lunar months).

' $p$ ' value less than 0.05 was considered to be statistically significant

\begin{tabular}{|c|c|c|c|c|c|c|c|}
\hline Sr. no. & Parameters & Side & 4 months & 5 months & 6 months & 7 months & ' $\boldsymbol{p}^{\prime}$ value \\
\hline \multirow{2}{*}{1} & Length of & Left & $16.7 \pm 1.6$ & $16.8 \pm 0.4$ & $17.7 \pm 0.7$ & $18.1 \pm 2.2$ & 0.29 \\
& petrous bone & Right & $17.7 \pm 2.06$ & $17.7 \pm 1.9$ & $17.37 \pm 1.5$ & $15.8 \pm 1.2$ & 0.14 \\
\hline \multirow{2}{*}{2} & \multirow{2}{*}{ Ant. SCC L } & Left & $1.6 \pm 0.2$ & $1.5 \pm 0.11$ & $1.47 \pm 0.2$ & $1.6 \pm 03$ & 0.48 \\
& & Right & $1.51 \pm 0.16$ & $1.55 \pm 0.18$ & $1.52 \pm 0.12$ & $1.57 \pm 0.2$ & 0.87 \\
\hline \multirow{2}{*}{3} & \multirow{2}{*}{ Ant. SCC H } & Left & $0.46 \pm 0.08$ & $0.47 \pm 0.05$ & $0.45 \pm 0.05$ & $0.41 \pm 0.07$ & 0.43 \\
& & Right & $0.46 \pm 0.05$ & $0.47 \pm 0.06$ & $0.44 \pm 0.06$ & $0.42 \pm 0.04$ & 0.25 \\
\hline \multirow{2}{*}{4} & \multirow{2}{*}{ Post. SCCL } & Left & $1.5 \pm 0.2$ & $1.5 \pm 0.09$ & $1.5 \pm 0.2$ & $1.6 \pm 0.2$ & 0.81 \\
& & Right & $1.57 \pm 0.12$ & $1.51 \pm 0.15$ & $1.57 \pm 0.07$ & $1.41 \pm 0.11$ & 0.07 \\
\hline \multirow{2}{*}{5} & \multirow{2}{*}{ Post. SCC H } & Left & $0.51 \pm 0.1$ & $0.52 \pm 0.06$ & $0.52 \pm 0.06$ & $0.49 \pm 0.11$ & 0.93 \\
& & Right & $0.53 \pm 0.09$ & $0.56 \pm 0.08$ & $0.52 \pm 0.1$ & $0.48 \pm 0.08$ & 0.37 \\
\hline \multirow{2}{*}{$\mathbf{6}$} & \multirow{2}{*}{ Lat. SCCL } & Left & $1.26 \pm 0.15$ & $1.28 \pm 0.09$ & $1.36 \pm 0.15$ & $1.36 \pm 0.2$ & 0.52 \\
& & Right & $1.36 \pm 0.18$ & $1.29 \pm 0.13$ & $1.19 \pm 0.11$ & $1.27 \pm 0.08$ & 0.13 \\
\hline \multirow{2}{*}{$\mathbf{7}$} & \multirow{2}{*}{ Lat. SCC H } & Left & $0.41 \pm 0.09$ & $0.42 \pm 0.07$ & $0.42 \pm 0.08$ & $0.36 \pm 0.05$ & 0.28 \\
& & Right & $0.41 \pm 0.08$ & $0.42 \pm 0.08$ & $0.38 \pm 0.05$ & $0.31 \pm 0.04$ & 0.04 \\
\hline \multirow{2}{*}{$\mathbf{8}$} & \multirow{2}{*}{ Cochlea L } & Left & $0.56 \pm 0.05$ & $0.54 \pm 0.05$ & $0.55 \pm 0.07$ & $0.58 \pm 0.08$ & 0.004 \\
& & Right & $0.6 \pm 0.02$ & $0.67 \pm 0.3$ & $0.65 \pm 0.04$ & $0.68 \pm 0.07$ & 0.59 \\
\hline \multirow{2}{*}{$\mathbf{9}$} & \multirow{2}{*}{ Cochlea B } & Left & $0.4 \pm 0.03$ & $0.41 \pm 0.05$ & $0.43 \pm 0.06$ & $0.45 \pm 0.07$ & 0.78 \\
& & Right & $0.36 \pm 0.02$ & $0.4 \pm 0.06$ & $0.42 \pm 0.07$ & $0.48 \pm 0.05$ & 0.68 \\
\hline \multirow{2}{*}{$\mathbf{1 0}$} & \multirow{2}{*}{ Cochlea H } & Left & $0.32 \pm 0,01$ & $0.34 \pm 0.03$ & $0.35 \pm 0.04$ & $0.36 \pm 0.07$ & 0.31 \\
& & Right & $0.3 \pm 0.01$ & $0.28 \pm 0.03$ & $0.22 \pm 0.05$ & $0.26 \pm 0.04$ & 0.64 \\
\hline
\end{tabular}

Regression equation obtained

1. CR length $=220.76+170.42 *$ cochlear length

2. CR length $=330.774-226.254 *$ lateral semicircular canal height 


\section{DISCUSSION}

The inner ear structures, including the membranous labyrinth, develop from the otic placode, (which is a thickening of the surface ectoderm of the embryonic head) [4-6]. The membranous labyrinth includes the cochlea, vestibule, semicircular canals, and the endolymphatic duct and sac. Development of the inner ear begins at 21 to 24 days' gestation. The margins of the placode invaginate and appose to form a simple cavity called the otocyst. The otocyst sinks below the surface and loses continuity with the overlying ectoderm $[4,6]$.

At 5 to 6 weeks, a diverticulum buds from the otocyst forming the endolymphatic sac, followed by the buds for the cochlea and vestibule. At 7 to 8 gestational weeks, formation of the membranous semicircular canals begins. The superior canal develops first, followed by the posterior and finally the lateral semicircular canal $[5,7,8]$. At 8 weeks, the membranous cochlea has achieved one to one and one-half turns. At 10 weeks, two turns have formed [8]. By 11 weeks, the full adult configuration of two and one-half to two and three-quarters turns are completed. The otocyst induces the surrounding mesenchyme to form cartilage that conforms to the shape of the membranous labyrinth, which it "finds." This cartilage model will form the bony otic capsule $[6,7]$.

The bony labyrinth inside the petrous temporal bone houses the inner ear, which contains the the organ of hearing in the cochlea and that of balance in the vestibule and semicircular canals. The modern human bony labyrinth is morphologically distinct from all other primates. The human labyrinth from a comparative and evolutionary perspective suggests that it attains its adult morphology before birth, so that direct comparison can be made between adult and juvenile specimens. The labyrinth may constitute a better representation of the genotypic makeup of an individual than do most other skeletal parts, because postnatal influences on the morphology by environmental or behavioral factors are minimal or absent.

Jeffery $N$ and Spoor $F$ 2004[9] studied prenatal growth and development of modern human labyrinth and observed radii of anterior semicircular canal, posterior semicircular canal, lateral semicircular canal as $2.41+0.83 \mathrm{~mm}, 2.24+0.85 \mathrm{~mm}$ and $1.70+0.67 \mathrm{~mm}$ respectively

Hassan et al 2014 [10] measured cochlear width and height and compared them between males and females. His observations were width $5.6+0.6 \mathrm{~mm}$ on left side and $5.6+0.4 \mathrm{~mm}$ on right side; height $3.6+0.4 \mathrm{~mm}$ on left side and $3.5+0.4 \mathrm{~mm}$ on right side respectively.

Odeh M 2013 [11] et al measured petrous bone on right as $10.80+3.8 \mathrm{~mm}$ and $10.15+3.7 \mathrm{~mm}$ on left side respectively.

In our study, we found length of petrous bone on left side $16.7+\ldots 1.6 \mathrm{~mm}$ and on right side17.7+2.06 $\mathrm{mm}$ at the age of 4 lunar months, $16.8+0.4 \mathrm{~mm}$ on left side and $17.7+1.9$ on right side at the age of 5 lunar months, $17.7+0.7 \mathrm{~mm}$ on left side and $17.37+1.5 \mathrm{~mm}$ on right side at the age of six lunar months, $18.1+2.2 \mathrm{~mm}$ on left side and $15.18+1.2 \mathrm{~mm}$ on right side at the age of 7 lunar months respectively.

The length of petrous bone observed by us in our study was on higher side compared to measurements done by Odeh et al.2013 [11].

We obtained the length and height of anterior semicircular canal, posterior semicircular canal, and lateral semicircular canal as recorded in table no .1, when we compared our data with that of Jeffery N and Spoor F2004 [9] our measurements were less in length as well as height.

We also measured cochlear length, width and height. The findings of our study are in correlation with findings of study done by Hassan et al 2014 [10].

In this modern cochlear implantation era, there is a growing interest in developing an atraumatic surgical technique designed to preserve cochlear function and minimize cochlear damage. To the best of our knowledge this is the only study done on bony labyrinth of fetal dry temporal bones. Even though MRI and HRCT are the choice to modality to measure cochlear size in cochlear implants studies like ours leave their mark too. As fetal cochlear development correlates with the surrounding petrosal morphology[9], studies concerning the relationship between the petrous bone measurement and genetic predisposition to congenital deafness[11] can be useful in diagnosis of causes of congenital 
deafness.

A study of larger sample size in correlation with imaging techniques may yield more precise measurements of bony labyrinth which can then be used in routine practice of otorhinolaryngology.

\section{CONCLUSION}

A new regression equation has been derived to predict CR length from length of cochlea and height of lateral semicircular canal as:

CR length $=220.76+170.42 *$ cochlear length

CR length $=330.774-226.254 *$ lateral semicircular canal height

M easurements of bony labyrinth in dry fetal temporal bones appear to be shorter than those described in literature. Studies like present study of anatomy of fetal bony labyrinth may lead to better understanding of congenital ear disorders.

\section{Conflicts of Interests: None}

\section{REFERENCES}

[1]. Arnold, W.H., Lang, T. Development of the membranous labyrinth of human embryos and fetuses using computer aided 3D - reconstruction.Ann. Anat. 2001;183(1):61-6.

[2]. Ellis, H. (2006).Clinical anatomy. 1led. Blackwell Publishing, Massachusetts.

[3]. Sato H, Sando I, Takahashi H. Sexual dimorphism and development of the human cochlea. Acta Otolaryngol.1991;111:1037-1040.
[4]. Jackler RK, Luxford WM , House WF. Congenital malformation of the inner ear: a classification based on embryogenesis. Laryngoscope 1987;97(40):2-14.

[5]. Schuknecht HF, Gulya AJ. Anatomy of the Temporal Bone with Surgical Implications. Philadelphia, Pa: Lea \& Febiger; 1986.

[6]. Sperber GH. Craniofacial Embryology. 4th ed. London, England: Wright, Butterworth Scientific; 1989.

[7]. Bast TH, Anson BJ. The Temporal Bone and the Ear. Springfield, II: Charles C Thomas; 1949.

[8]. Donaldson JA, Duckert LG, Lambert PM, Rubel EW. Surgical Anatomy of the Temporal Bone. New York, NY: Raven Press; 1992

[9]. Jeffery N, Spoor F. Prenatal growth and development of the modern human labyrinth. J Anat. 2004 Feb;204(2):71-92.

[10]. Hassan LA, Caroline Edward Ayad, Hassan HA , Abdalla EA,M ohamed ME. Global Advanced Research Journal of Medicine and Medical Science. June 2014;3(6):117-123.

[11]. Odeh M, Safa W, Ophir E, Grinin V, Hakim M, Bornstein J. The petrous portion of the temporal bone as shown on sonography between 14 and 40 weeks' gestation. J Ultrasound Med. 2013 Jun;32(6):989-93.

\section{How to cite this article:}

Anjali Gosavi, Rekha Hiremath. STUDY OF DEVELOPM ENT OF BONY LABYRINTH IN DRY FETAL TEM PORAL BONES. Int J Anat Res 2017;5(2.3):3896-3899. DOI: 10.16965/ijar.2017.210 